\title{
Note-Taking Assisted with Computers-A Practical Method to Build a Connection between Chinese Pinyin \& Characters
}

\author{
Wu Yang1, Isabella Kam² \\ ${ }^{1}$ Foreign Languages School, Hunan University of Commerce, Changsha, China \\ ${ }^{2}$ Confucius Institute, Woosong University, Daejeon, South Korea \\ Email:215221070@qq.com
}

How to cite this paper: Yang, W., \& Kam, I. (2018). Note-Taking Assisted with Computers-A Practical Method to Build a Connection between Chinese Pinyin \& Characters. Chinese Studies, 7, 328-342. https://doi.org/10.4236/chnstd.2018.74026

Received: September 18, 2018 Accepted: November 27, 2018 Published: November 30, 2018

Copyright $\odot 2018$ by authors and Scientific Research Publishing Inc. This work is licensed under the Creative Commons Attribution International License (CC BY 4.0).

http://creativecommons.org/licenses/by/4.0/

\begin{abstract}
Chinese beginners often find themselves in struggling for learning complicated Chinese characters (also known as Hanzi), after the acquisition of Chinese pronunciation (Chinese Phonetic Alphabets, also called Pinyin). Actual experience of living and studying in China exposes a fact that people on daily basis are not using Pinyin to assist pronunciation. All means of social media only have Hanzi for people to recognize. The connection between Pinyin and Hanzi is a difficult part to accomplish for Chinese language beginners. Based on several years of teaching experience of Chinese language to speakers of other languages and working memory drill in English-Chinese interpretation, the author explores a practical way to build this connection between Pinyin and Hanzi by taking-notes using computers and mobile phones in class. In alliance with fun language teaching methodologies, i.e., the Audiolingual method, Communicative Language Teaching (CLT) to reassure the memory rehearsal drill in association with imaginary situations. The research experiment results show that this method can stimulate beginners' learning enthusiasm and arouse their confidence and initiative in the long-run Chinese language learning process and it can facilitate Chinese beginners to better communicate in the fast-changing social media.
\end{abstract}

\section{Keywords}

Note-Taking Assisted with Computer, Connection between Pinyin \& Hanzi, Memory Rehearsal, Initiative

\section{Introduction}

\section{Global Chinese Learning Heat and Chinese Language Beginners' Dilemma}

In the world context of artificial intelligence (AI), social media and digital mo- 
bile applications are allowing people to communicate easier and in wilder area. The world is more multilingual with AI machine translation. The rise of China makes Chinese language become more popular than ever before. The Chinese language population is increasing drastically in recent years. However, many complain that Chinese language is the world's most difficult language to learn due to the fact that it has two separate systems for pronunciation and writing.

The motivation of learning a language can be multiple. Apart from the purpose of studying, working and living in China, many declare that they learn the language out of sheer interest and intention of knowing the long standing and profound Chinese language and culture. They start their language and culture quest with great passion and confidence in learning Pinyin for the first month of learning process. However, many of them would soon find the dual separate Chinese language systems for pronunciation and writing very challenging and they hesitate in devoting time and energy in acquiring both. Some would struggle to decide whether to continue without learning the complicated strokes of Chinese characters. This learning journey would become low in accomplishment and less efficient in speaking and writing as time goes by. It would even hamper the entire Chinese learning due to the high drop rate of systematic Chinese learning after Pinyin process, especially for the overseas students coming to China for a degree without the requirement of obtaining HSK levels. (HSK is short for Hanyu Shuiping Kaoshi, Chinese Proficiency Test for other nationalities or other Chinese ethic group learners) (Wang, 2016). The dilemma for Chinese language beginner lies in whether to continue with the mastery of Pinyin only or going on with learning Hanzi, which seems to be two very distinct learning experiences. Pinyin learning is similar to learning many other languages which also can be marked with International Phonetic Alphabets (IPA), whereas, recognizing Hanzi requires more memory and culture awareness for better understanding in semantic level. This is, therefore, a long accumulating process due to the large number of Chinese characters forming from various combinations of strokes.

To solve Chinese beginner's dilemma, a practical way to build a connection between Pinyin and Hanzi is required so as to maintain learning zest and initiative when it comes to the more time-consuming and seemingly more complicated Hanzi learning phase.

\section{Literature and Definitions}

\subsection{Working Visual Memory Mechanism}

Real life language learning experience of many people proved that if without proper interference or memory reinforcing drill, the learning process can be low in outcome due to the limited capacity and duration of short-term memory (STM). However, if in a language class, the instructor can properly guide the learning process with practical memory reinforcing skills based on the cognitive psychological theories, the study outcome can be more fulfilling and fruitful (Baddeley \& Hitch, 1974).

Working memory is a cognitive system with a limited capacity (Miyake \& 
Shah, 1999). It is responsible for holding information temporarily available for processing. Working memory is important for reasoning and it is the guidance for decision-making and behavior (Antonino \& Gezinus, 2017). It is often used as a synonymous term with short-term memory, but some theorists consider the two forms of memory distinct, assuming that working memory allows for the manipulation of stored information, whereas short-term memory (STM) only refers to the short-term storage of information (Cowan, 2008). In comparison with working visual memory, STM (or "primary" or "active memory") is the capacity for holding, but not manipulating, a small amount of information in mind in an active, readily available state for a short period of time. For example, STM can be used to remember a phone number that has just been recited. The duration of STM (when rehearsal or active maintenance is prevented) is believed to be in the order of 15 to 30 seconds (McLeod, 2009). The most commonly cited capacity is The Magical Number Seven, Plus or Minus Two (which is frequently referred to as Miller's Law), despite the fact that Miller himself stated that the figure was intended as "little more than a joke" (Miller, 1956) and that Cowan (2008) provided evidence that a more realistic figure is $4 \pm 1$ units. Although STM has very limited capacity and duration, One important feature of STM is that there are plenty of memory rehearsal ways to strengthen the encoding process, which means the primarily acoustic or visual information being translated into sounds The encoding process of STM can be reinforced via various kinds of memory rehearsal drills, either from acoustic information to visual information, or from visual information to acoustic information (Mathy \& Feldman, 2011). The ultimate goal for STM rehearsal is to transfer STM to long-term memory, which can hold the information indefinitely (Malaia \& Wilbur, 2018).

Magro et al. (2018) showed that the storage capacity of visual working memory is about four objects and that this capacity does not depend on the number of features making up the objects. Thus, visual working memory seems to process integrated objects rather than individual features, just as verbal working memory handles higher-order "chunks" instead of individual features or letters (Kowialiewski \& Majerus, 2018). The same is true in learning Chinese Hanzi, it will be very low efficient if students try to memorize single characters or phrases without organizing them in a group or sentence to form higher level chunks.

In this research, the author designs an experiment to build a connection between Pinyin and Hanzi, which applies the working memory mechanism in Chinese Hanzi memory consolidation with the aid of rehearsal drill by displaying the repeated visions of Chinese characters when typing in the required Chinese Pinyin and text via listening. This experiment is strictly carried on the basis of transferring visual working memory in combination of acoustic memory assistance, following a carefully designed memory reinforcement drill by repeating, retelling and alter-situation paraphrasing.

\subsection{Language Interpretation and Note-Taking Skills}

Language interpretation refers to the oral translation activity of one language 
into another. It is a process in which one produces a first and final translation on the basis of a one-time exposure to an expression in a source language $(\mathrm{Wu}$, 2000).

The most common two modes of interpreting are simultaneous interpreting, which is done at the time, or 2 seconds lagging behind of the exposure to the source language, and consecutive interpreting, which is done at breaks to this exposure (Zhong, 2013).

The prerequisite for applying this method in Chinese language teaching class is that the students should have good enough English command. The "good enough" refers to the language proficiency level which is above the students' target language proficiency level. In this research, the 16 South Korean students have proficient English level which is well above their target Chinese language proficiency level, therefore, the interpretation and note-taking drills in the experiment have yielded in satisfactory results. Traditionally, note-taking is done with a pen and notebook, similarly to the Korean “받아쓰기” technique, which means dictation. The difference between note-taking and dictation is shown on the notes being taken. Dictation requires the students to write down every single word, phrases and sentences, while note-taking allows students to mark with every possible symbols, signs, acronyms, abbreviations etc to bring back memory for the later required retelling exercise ( $\mathrm{Wu}, 2008)$. In this experiment, the researcher combines the dictation and note-taking skills into real classroom drill and final assessment and used them alternatively for better learning outcome.

\subsection{Traditional Chinese Language Teaching Methodologies}

Language teaching methods in general should avoid being rigid and stiff, otherwise, the class would inevitably turn to be tedious and lifeless. To encourage students' creativity and initiative, a Chinese language class should be specifically designed to suit students' study motivation and single class objectives. Most traditional approaches for teaching Chinese are teacher centered with the language instructor being the main authority. Students are regarded as "empty vessels" whose primary role is to passively receive information (via lectures and direct instruction) with an ultimate goal of achieving good testing and assessment scores (Uzundag \& Küntay, 2018). This phenomenon is very prominent in the research experiment target group, which is a class of 16 South Korean Chinese language beginners. It appeared to the researcher that in the beginning of the 3-week experimental teaching, their primary motivation and great concern is to achieve $\mathrm{A}+$ in the final assessment. It is also true for many untrained Chinese language instructors to have view their primary role of a teacher to be pass knowledge and information onto their students, without putting attention to make the classroom to be student-centered. The traditional Chinese class can be very boring if the instructor only applies the simple repeating technique for the entire class. In Student-Centered Approach, however, teachers and students play an equally active role in the learning process (Westwood, 2008). The teacher's primary role is to coach and facilitate student learning and overall comprehen- 
sion of material. Student learning is measured through both formal and informal forms of assessment, including group projects, student portfolios, and class participation. Teaching and assessments are connected; student learning is continuously measured during teacher instruction. Commonly used teaching methods may include class participation, demonstration, recitation, memorization, or combinations of these.

To be more specific, there are plenty of language teaching methodologies applicable in a traditional Chinese language class. Most commonly used methodologies include Communicative Language Teaching (CLT), the Audiolingual method and Situation Role play etc.

In combination with the note-taking with computers drill, the research applies the above mentioned methods in designing the experiment and assessment and anticipates not only a more active and lively class atmosphere, but also a more productive learning outcome.

\section{Method \& Experiment Design}

This a empirical study for testifying the assumption of connection between Pinyin and Hanzi can be built: The higher proficient level in Pinyin, the faster and easier for students to learn Hanzi. The purpose of this experiment is to apply working memory rehearsal mechanism, language interpretation and note-taking skills into Chinese language teaching to ensure students Chinese proficiency over a certain domain of topics in three weeks of training. Considering the targeted group is a 16-student class from South Korea, the researcher did a pre-test of Pinyin dictation to know whether all students meet the prerequisite of this experiment. The design of Pinyin dictation test is as follows:

The instructor prepares the listening recording together with the transcript in advance to guarantee a clear and standard pronunciation without any unexpected classroom interference.

1) Listen and identify Pinyin Initials, finals and single syllables, which cover $25 \%$ of the test. Students need to note down every single pronounced Pinyin.

2) Listen and identify Pinyin for words and phrases, which cover $50 \%$. Students are required to note down correctly the Pinyin, including the right initial, final and tone for the pronunciation.

3) Listen and write Pinyin for short Chinese sentences, which cover $25 \%$. Students should note down correctly the punctuation and Pinyin, including the right initial, final and tone for the pronunciation.

Only one student failed in the Pinyin Test and chose to drop from this 3-week class experiment.

Pinyin Dictation test result is shown in Table 1.

The experiment is continued with a three-week training of 15 South Korean Chinese language beginners who has Chinese Pinyin acquisition as the prerequisite of carrying this experiment. The one student who failed in the Pinyin dictation test chose to drop from the training even after the research has tried to persuade him to stay. 
Table 1. Prerequisite pinyin dictation test result.

\begin{tabular}{cccccc}
\hline No. & $\begin{array}{c}\text { Pinyin Initials, } \\
\text { Finals \& } \\
\text { syllables }\end{array}$ & $\begin{array}{c}\text { Pinyin for } \\
\text { words and } \\
\text { Phrases }\end{array}$ & $\begin{array}{c}\text { Pinyin for short } \\
\text { sentences }\end{array}$ & Total & $\begin{array}{c}\text { Length of Chinese } \\
\text { Learning }\end{array}$ \\
\hline 1 & 24 & 50 & 25 & 99 & 60 months \\
2 & 23 & 48 & 25 & 96 & 24 months \\
3 & 24 & 48 & 21 & 93 & 6 months \\
4 & 23 & 50 & 19 & 92 & 4 months \\
5 & 25 & 46 & 20 & 91 & 3 months \\
6 & 20 & 45 & 25 & 90 & 1 month \\
7 & 19 & 46 & 23 & 88 & 1 month \\
8 & 17 & 40 & 18 & 85 & 1 month \\
9 & 20 & 42 & 22 & 84 & 1 month \\
10 & 21 & 43 & 19 & 83 & 1 month \\
11 & 23 & 40 & 18 & 81 & 12 months \\
12 & 19 & 39 & 22 & 80 & 12 months \\
13 & 19 & 47 & 10 & 76 & 12 months \\
14 & 22 & 36 & 12 & 70 & 12 months \\
15 & 21 & 29 & 14 & 64 & 36 months \\
16 & 15 & & $45($ drop $)$ & 48 months \\
\hline
\end{tabular}

Another premise for this classroom language experiment is for students to have computers that installed two softwares which will enable them to type in Chinese Hanzi and mark Pinyin automatically. Two software sare Sogou Pinyin and WPS office. In the training, the instructor has asked students to prepare their own laptops or mobile phones which can be installed with the two required software and function the same when typing in Chinese. The note taking with computer drill has last throughout 3 weeks with in-class spontaneous note-taking exercises, 2 scheduled quizzes, 2 home assignments and one final examination. An in-class note-taking exercise with Communicative Language Teaching and Audiolingual Method is shown in the following:

Directions for the class: This exercise lasts for 30 minutes with a purpose to encourage students to ask questions using the given question pattern. The whole process is mingled in a game named Truth or Dare. Students need to come out with one similar pattern question but in different situations to ask each other. After being provided with the example question, every student is asked to prepare the main question and at least three supportive questions to ask about details in the situation using the 5 -whs question pronouns within 5 minutes. During this 5 minutes, they need to confirm the grammar, vocabulary and sentence pronunciation and type in the sentence using WPS and Sogou Pinyin software on their computer or mobile phone screens. The instructor will move around to confirm, to assist and to solve their problems if any. 
The structure provided by the instructor: 主语(你) + 有没有 + 动词 + 过 + 宾语?

(Have you ever + done (V-ed) + something?)

Example 你有没有打过群架? Have you ever been in a group fight before?

The supportive questions for digging details:

1) 你什么时候打的群架? (When was it?)

2) 你们们昌昌隻? (Who did you fight?)

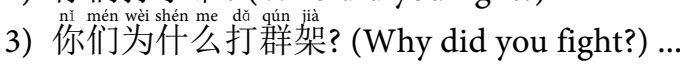

This is a choice question and students can choose to answer from yes or no. If yes, they reply 有, if no, they reply 没有. The exercise is done in a game and students are always interested to dig for more details by asking supportive questions using what, when, why, which, where and how. If students being asked felt a little embarrassed to reveal details, they can choose to DARE by accepting minor punishment such as going down to the first floor and come back to the classroom by stairs in 3 minutes. The whole learning process is fun and informative. The instructor has ensured students to use the given sentence pattern to form a similar question by typing in on the screen and also encouraged them to speak up out loud and communicate with each other in a pleasant way. Some students revealed that the class atmosphere is light and enjoyable and "I have learned more vocabulary and spoken as much Chinese voluntarily as my past 5 years combined".

Questions provided by students are also interesting:

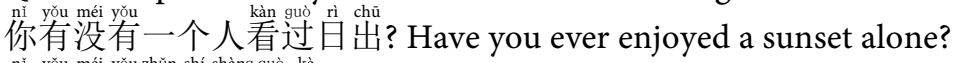

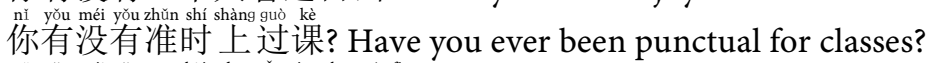

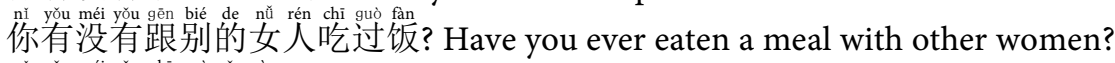

你有没有吃过狗苓? Have you ever eaten dog meat?

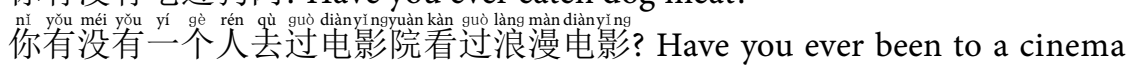

for a romantic movie alone?

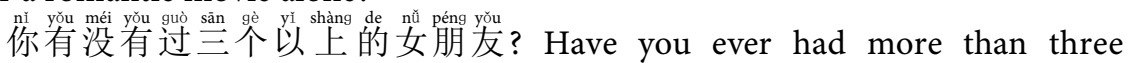
girlfriends?

As the Magic number 7 (plus or minus two) provides evidence for the capacity of short term memory. Most adults can store between 5 and 9 items in their short-term memory. This idea was put forward by Miller (1956) and he called it the magic number 7. He though that short term memory could hold 7 (plus or minus 2 items) because it only had a certain number of "slots" in which items could be stored.

However, Miller didn't specify the amount of information that can be held in each slot. Indeed, if we can "chunk" information together we can store a lot more information in our short term memory (Li, 2017).

The duration of short term memory seems to be between 15 and 30 seconds, according to Atkinson \& Shiffrin (1971). Items can be kept in short term memory by repeating them verbally (acoustic encoding), a process known as rehearsal. 
In the above designed exercise, the structure provided has 5 chunks (主语(你) + 有没有 + 动词 + 过 + 宾语?) which is within moderate STM capacity. It should not be difficult for students to memorize. The instructor underlined three places and asked the students to replace with other words and continue to rehearse the same pattern over and over again in 30 minutes by several memory reinforcing techniques, i.e., association (imaginary situations), visualization (typing in and displaying on screens), audiolingual rehearsal (repeating listening and speaking) and CLT (Communicative Language Teaching by engaging in conversations). The aim was to transfer STM to long-term memory which is not easily forgotten.

\section{Findings}

The three-week class training was designed to familiarize students to use Chinese language type-in software to communicate and express themselves has achieved expected experiment results. All 15 students have followed closely the experiment steps and have grasped basic skills of using the software to type in Chinese. The 15 students all reported with confidence in chatting and typing in Chinese Hanzi with their friends on social media applications. Some revealed that this training is very thought-provoking because they are always required to come up with different situations using provided sentence patterns. The process is guided and they have faith in speaking even creating new sentences rather than being asked to repeat with boredom. The results showed no obvious evidence for a connection between longer years of Chinese study and good Pinyin proficiency. Instead, some students who learned the language for only weeks or months have better Pinyin level than those who studied for years.

Table 2 shows students' final assessment score and the rank comparison with the prerequisite dictation test:

However, to compare the final assessment score with the prerequisite Pinyin test score, it is easy to find a correlation between actual Pinyin proficiency and efficient Hanzi learning $(\mathrm{p}<0.000)$. Correlation between prerequisite pinyin test score and final assessment score is shown below in Table 3:

However, results showed that learners with longer Chinese learning time had no significant advantage in the final assessment score $(\mathrm{P}=0.34>0.05)$. Table 4 demonstrates the correlation analysis results:

A possible explanation to the fact that longer time of Chinese learning won't yield in greater scores in the final assessment can be the discontinuous learning of the language. Students who claimed that they have learned the language for 4 years didn't necessarily learn Chinese on a regular basis as a major or media language for class and living, with individual differences in learning methods and intensity during their initial Pinyin learning process being the other reason.

In the final assessment, students are required to fulfill three tasks: one is the type-in examination which covers $40 \%$, the other two are oral interpretation from English (or Korean) to Chinese (20\%) and a dialogue done with a group 
Table 2. Final Assessment Score.

\begin{tabular}{cccccc}
\hline No. & $\begin{array}{c}\text { Type-in Exam } \\
\text { Score }(40 \%)\end{array}$ & $\begin{array}{c}\text { Interpretation } \\
(20 \%)\end{array}$ & $\begin{array}{c}\text { Dialogue } \\
(40 \%)\end{array}$ & $\begin{array}{c}\text { Total } \\
(100 \%)\end{array}$ & $\begin{array}{c}\text { Rank Comparison } \\
\text { with Pinyin } \\
\text { Dictation Test }\end{array}$ \\
\hline 1 & 39.5 & 20 & 40 & 99.5 & 1,1 \\
2 & 39 & 20 & 40 & 99 & 2,2 \\
3 & 38.5 & 19 & 40 & 97.5 & 4,3 \\
4 & 38 & 20 & 40 & 98 & 3,4 \\
5 & 37.5 & 18 & 40 & 95.5 & 5,5 \\
6 & 37 & 18 & 38 & 93 & 6,6 \\
7 & 36.5 & 17 & 38 & 91.5 & 8,7 \\
8 & 36 & 18 & 38 & 92 & 7,8 \\
9 & 36 & 16 & 37 & 89 & 9,10 \\
10 & 33 & 20 & 37 & 90 & 10,9 \\
11 & 32 & 18 & 36 & 86 & 11,11 \\
12 & 32 & 18 & 35 & 85 & 12,12 \\
13 & 30 & 17 & 34 & 81 & 13,13 \\
14 & 22 & 16 & 32 & 70 & 14,14 \\
15 & 19 & 15 & & 64 & \\
\hline
\end{tabular}

Table 3. Correlation between prerequisite pinyin \& final assessment score.

\begin{tabular}{|c|c|c|c|}
\hline \multicolumn{4}{|c|}{ Correlations } \\
\hline & & Prerequisite & Final \\
\hline & & Pinyin Score & Assessment \\
\hline \multirow{5}{*}{ Prerequisite Pinyin Score } & Pearson Correlation & 1 & $0.977^{\star *}$ \\
\hline & Sig. (2-tailed) & & 0.000 \\
\hline & $\begin{array}{l}\text { Sum of Squares and } \\
\text { Cross-products }\end{array}$ & 1292.400 & 1365.700 \\
\hline & Covariance & 92.314 & 97.550 \\
\hline & $\mathrm{N}$ & 15 & 15 \\
\hline \multirow{5}{*}{ Final Assessment } & Pearson Correlation & $0.977^{\star *}$ & 1 \\
\hline & Sig. (2-tailed) & 0.000 & \\
\hline & $\begin{array}{l}\text { Sum of Squares and } \\
\text { Cross-products }\end{array}$ & 1365.700 & 1511.933 \\
\hline & Covariance & 97.550 & 107.995 \\
\hline & $\mathrm{N}$ & 15 & 15 \\
\hline
\end{tabular}

**. Correlation is significant at the 0.01 level (2-tailed).

mate (40\%). The type-in exams will be done with prepared recording and transcript. The interpretation and dialogue parts are evaluated with detailed designed speaking test evaluation Rubric. The following is the instructions for the final assessment: 
Table 4. Correlation between final assessment score and length of chinese learning.

\begin{tabular}{cccc}
\hline \multicolumn{4}{c}{ Descriptive Statistics } \\
\hline & Mean & Std. Deviation & $\mathrm{N}$ \\
Final Assessment & 88.7333 & 10.39208 & 15 \\
Length of Chinese & 15.6000 & 17.30318 & 15 \\
Learning (months) & Correlations & \\
\hline & Final Assessment & Length of Chinese \\
& Pearning \\
\hline Final Assessment & Sig. (2-tailed) & 1 & -0.265 \\
& N & 15 & 0.340 \\
Length of Chinese & Pearson Correlation & -0.265 & 15 \\
Learning & Sig. (2-tailed) & 0.340 & 1 \\
& N & 15 & 15 \\
\hline
\end{tabular}

第一部分: 汉字输入测试, 40 分, (第 9-10 课录音内容)

听录音, 在电脑上使用 Sogou 拼音输入法将听到的录音文字输入到 WPS 里, 完成输入后请给文字标注拼音, 输入的文本请选择 Times New Roman 字 体, 16 号, 在 30 分钟内将输入的文本发送至 mirandawu@sis.ac.kr.

Part One (Type-in Chinese characters, 40 points, Lesson 9 \& 10)

Directions: Listen to the recording and type in the information in Chinese you hear using WPS and Sogou software. You should add Pinyin to (above) the characters. When you finish all the typing, select all typed-in information and choose TIMES NEW ROMAN font with a size of 16. Part one will cover Lesson 9 and lesson 10 of the textbook.

\section{第二部分：英汉口译 (20 分, 第 11-12 课内容)}

根据教材第十一课和第十二课的内容, 教师说英语, 学生说汉语, 考察学 生对词汇和句型的熟练度、语音和汉语表达能力。口语测试将会被录音。

Part Two (English-Chinese Interpretation, 20 points, Lesson 11 \& Lesson 12 )

Directions: Students are required to interpret from English to Chinese what the instructor provided on-spot. This part will cover Lesson 11 and Lesson 12 of the textbook. This part is designed to test students' language proficiency over vocabulary and sentences, pronunciation and language expression ability. The speaking test will be recorded.

第三部分: 对话(20 分, 每组 10 分钟)

学生两两一组, 就给定场合考察汉语会话、配合完成交流和对话的能力。(提 出并回复问题, 组织对话, 引导对话)。口语测试将会被录音。

\section{Part Three Conversation (20 points, 10 minutes for each group)}

Two Students in a group to conduct a conversation on a given topic. This is to evaluate students team spirit and ability to complete a situational dialogue by asking and answering questions, organizing and leading a conversation in Chinese. Speaking test will be recorded. 
Each group chooses one topic from the following situations:

参加一场面试(面试官和求职者) Interviewee and interviewer

晚上吃什么 What to have for dinner

暑假去中国玩 Planning to go to China for summer vacation

周末做什么 What to do this weekend

Students final assessment score has shown obvious positive correlation with their prerequisite Pinyin acquisition. The more proficient they can use pinyin, the faster and more accurate when they type in Chinese Hanzi using online software with AI association technology which can automatically correct the typing errors based on the users accustomed behavior and habits. These functions are very user-friendly to Chinese beginners who are not very confident communicating to people around in Chinese language. It largely lowers the difficulties to hand-write Hanzi which reported by many international students as drawing and recognizing pictures especially when it comes to Chinese calligraphy. The modern fonts can be chosen when they are doing typing in exercise and allow them to feel different styles of Hanzi writing and memorize them easily and efficiently on a daily basis.

What's more, after 3 weeks training using CLT and audiolingual method in combination with working memory reinforcing drill, all 15 students are able to communicate with the researcher on screen using emails or mobile social media applications in Chinese for any daily topics whenever they recall acquired vocabulary and sentence patterns. Once the connection between Pinyin and Hanzi was built, students are not only more confident in expressing themselves in class, but also becoming more initiative and creative on screen after class. The ultimate goal for learning a language is to communicate, therefore, the research has satisfied this primary goal of using Chinese language for beginners to express themselves freely in class and after class.

\section{Discussion}

This 3-week experiment of note-taking with computers to build a connection between Chinese Pinyin and Hanzi is based on students' acquisition of Pinyin. If the trainees are absolute beginners, they should be first receiving a systematic training of Chinese Pinyin. In China, 3 to 5 year old children usually receive a 3 to 6 months education of systematic Pinyin before they start to learn Hanzi. For International students studying in China, Chinese National Education Ministry suggests a minimum of 2 weeks concentrated time for Pinyin prior any Chinese Hanzi input to guarantee a better learning outcome. Therefore, if applying this experiment to another group, a prerequisite Pinyin dictation is also necessary to know whether they can be directly guided through this training. If they are absolute beginners, another 3 weeks of Pinyin training is required before this experiment.

Another premise to innovate Chinese language teaching with CTL and audiolingual methods in this experiment is for the students and instructor to have 
good English command so as to interact to the maximum extent in class. However, this sometimes is not available due to the current main stream Chinese language teaching method is the target language (Chinese) immersion education instead of bilingual, letting alone multilingual immersion which largely motivates students to participate in communication and class activities.

\section{Conclusion}

Chinese language class needs to be live and fun. The teaching methods should be flexible in order to seek stimulation and to combine with various students' learning motivations. In update with the current multilingual context in all kinds of social media, Chinese language class should also be of creativity and novelty in combination of practical teaching methods. For those who have any past language learning experience, they should be familiar with one saying: The palest ink is better than the best memory (好记性不如烂笔头). In other words, the connection between Chinese Pinyin and Hanzi should be reinforced in class to the maximum extent for better learning outcomes. This research carried out a three week experiment for a group of 15 South Korean Chinese beginners to better communicate with Chinese language using computers software and mobile phone, social media applications. The training process is designed with scientific working memory mechanism and language teaching methods, CLT and audiolingual methods in particular to stimulate students' learning enthusiasm and creativity.

The note-taking drill in language interpretation was done with computers in this experiment and with the help of modern artificial intelligence to generalize Pinyin and confirm pronunciation. The improved learning efficiency is a natural response to the modern technologies and innovative teaching methods. The students who participated in the drill have demonstrated active interaction and enthusiasm in class and have revealed faith in the future language learning endeavors.

Therefore, this experiment has satisfied the designed goals of building a connection between students' Pinyin with Hanzi by communicating with confidence and initiatives. It's applicable to any level of Chinese language learners with a prerequisite of Pinyin learning for a minimum of 2 weeks prior the experiment.

The author takes a hint from this research that, teaching methods in the digital era are certainly changing in the world of AI. It is up to teachers themselves to learn how to weave technology into their profession. Appendix is evidence of one student's final examination paper in which he has demonstrated type-in skills and achieved a satisfactory outcome.

\section{Conflicts of Interest}

The authors declare no conflicts of interest regarding the publication of this paper. 


\section{References}

Atkinson, R. C., \& Shiffrin, R. M. (1971). The Control Processes of Short-Term Memory. Institute for Mathematical Studies in the Social Sciences, Stanford University.

Baddeley, A. D., \& Hitch, G. (1974). The Psychology of Learning and Motivation: Advances in Research and Theory(Vol. 8, pp. 47-89). New York: Academic Press.

Cowan, N. (2008). What Are the Differences between Long-Term, Short-Term, and Working Memory? Progress in Brain Research, 169, 323-338. https://doi.org/10.1016/S0079-6123(07)00020-9

Kowialiewski, B., \& Majerus, S. (2018). The Non-Strategic Nature of Linguistic Long-Term Memory Effects in Verbal Short-Term Memory. Journal of Memory and Language, 101, 64-83. https://doi.org/10.1016/j.jml.2018.03.005

Li, J. (2017). An Review on the Interpretation Memory Research. Translation Horizons, 1, 153-154.

Magro, L. O., Attout, L., Majerus, S., \& Szmalec, A. (2018). Short- and Long-Term Memory Determinants of Novel Word form Learning. Cognitive Development, 4, 47.

Malaia, E., \& Wilbur, R. B. (2018). Visual and Linguistic Components of Short-Term Memory: A Common Neural Model for Spoken and Sign Languages. Cortex, 3, 34. https://doi.org/10.1016/j.cortex.2018.05.020

Mathy, F., \& Feldman, J. (2011). What's Magic about Magic Numbers? Chunking and Data Compression in Short-Term Memory. Cognition, 3, 122.

McLeod, S. A. (2009). Short-Term Memory. https://www.simplypsychology.org/short-term-memory.html

Miller, G. (1956). The Magical Number Seven, Plus or Minus Two: Some Limits on Our Capacity for Processing Information. The Psychological Review, 63, 81-97. https://doi.org/10.1037/h0043158

Miyake, A., \& Shah, P., eds. (1999). Models of Working Memory: Mechanisms of Active Maintenance and Executive Control. Cambridge: Cambridge University Press. https://doi.org/10.1017/CBO9781139174909

Raffone \& Wolters, (2017). A Cortical Mechanism for Binding in Visual Working Memory. Journal of Cognitive Neuroscience, 13, 6.

Uzundag, B. A., \& Küntay, A. C. (2018). Children's Referential Communication Skills: The Role of Cognitive Abilities and Adult Models of Speech. Journal of Experimental Child Psychology, 172, 72-95. https://doi.org/10.1016/j.jecp.2018.02.009

Wang, F. (2016). Is HSK a Good Indicator of International Students' Chinese Proficiency? Chinese Language Education, 8, 76.

Westwood, P. (2008). What Teachers Need to Know about Teaching Methods. Camberwell, Vic: ACER Press.

Wu, Y. (2008). On the Process and Training Strategies of Consecutive Interpretation (CI) under the Perspective of Memory Psychology. Shanghai: Central South Univeristy Press.

$\mathrm{Wu}, \mathrm{Y} . \mathrm{N}$. (2000). On the Teaching of English-Chinese Consecutive Interpretation. Foreign Languages and Translation, 6, 56.

Zhong, W. H. (2013). Memory Training in Interpreting. Chinese Translation, 2, 30-33. 
Appendix: One Student's Type-In Examination Paper
201801040
Woo jung bin
1. Uit isid
2. 造抽消造

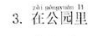
4. 此素饿。
5. 等么是?

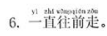

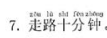
8. 图苇馆不远。
9. 我枈不知通。

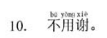

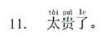

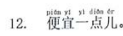

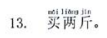

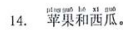

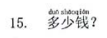

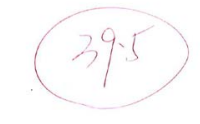

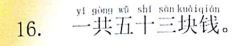
17. 哪个颜色?
18. 等期集
19. 哈密的
20. 好吃。

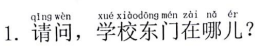

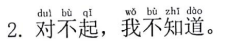

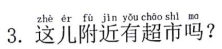

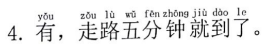

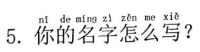

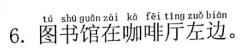
7. 今留天得䈨器!

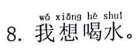

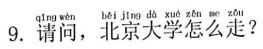

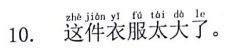

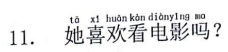




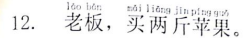

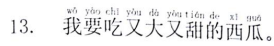
14. 这个岁少少㭜?

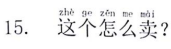

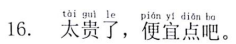

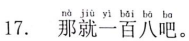

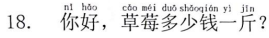

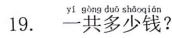

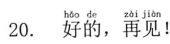

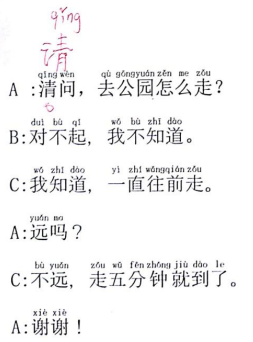

C: 不用谢!

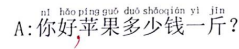

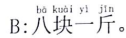

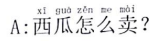

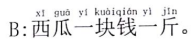

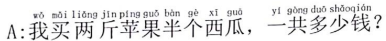

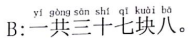

